\title{
Association of self-perceived income sufficiency with cognitive impairment among older adults: a population-based study in India
}

\author{
T. Muhammad, Shobhit Srivastava* (1) and T. V. Sekher
}

\begin{abstract}
Background: Greater cognitive performance has been shown to be associated with better mental and physical health and lower mortality. The present study contributes to the existing literature on the linkages of self-perceived income sufficiency and cognitive impairment. Study also provides additional insights on other socioeconomic and health-related variables that are associated with cognitive impairment in older ages.

Methods: Data for this study is derived from the 'Building Knowledge Base on Population Ageing in India'. The final sample size for the analysis after removing missing cases was 9176 older adults. Descriptive along with bivariate analyses were presented to show the plausible associations of cognitive impairment with potential risk factors using the chi-square test. Also, binary logistic regression analysis was performed to provide the relationship between cognitive impairment and risk factors. The software used was STATA 14.

Results: About $43 \%$ of older adults reported that they had no source of income and $7.2 \%$ had income but not sufficient to fulfil their basic needs. Older adults with income but partially sufficient to fulfil their basic needs had $39 \%$ significantly higher likelihood to suffer from cognitive impairment than older adults who had sufficient income [OR: 1.39; OR: 1.21-1.59]. Likelihood of cognitive impairment was low among older adults with asset ownership than older adults with no asset ownership [OR: 0.83; Cl: 0.72-0.95]. Again, older adults who work by compulsion (73.3\%) or felt mental or physical stress due to work (57.6\%) had highest percentage of cognitive impairment. Moreover, older adults with poor self-rated health, low instrumental activities of daily living, low activities of daily living, low subjective well-being and low psychological health were at increased risk for cognitive impairment.

Conclusion: The study highlights the pressing need for care and support and especially financial incentives in the old age to preserve cognitive health. Further, while planning geriatric health care for older adults in India, priority must be given to financially backward, with no asset ownership, with poor health status, older-older, widowed, and illiterate older individuals, as they are more vulnerable to cognitive impairment.
\end{abstract}

Keywords: Cognitive impairment, SES, Older adults, Regression, India

\footnotetext{
* Correspondence: shobhitsrivastava889@gmail.com International Institute for Population Sciences, Mumbai, Maharashtra 400088, India

(c) The Author(s). 2021 Open Access This article is licensed under a Creative Commons Attribution 4.0 International License, which permits use, sharing, adaptation, distribution and reproduction in any medium or format, as long as you give appropriate credit to the original author(s) and the source, provide a link to the Creative Commons licence, and indicate if changes were made. The images or other third party material in this article are included in the article's Creative Commons licence, unless indicated otherwise in a credit line to the material. If material is not included in the article's Creative Commons licence and your intended use is not permitted by statutory regulation or exceeds the permitted use, you will need to obtain permission directly from the copyright holder. To view a copy of this licence, visit http://creativecommons.org/licenses/by/4.0/. The Creative Commons Public Domain Dedication waiver (http://creativecommons.org/publicdomain/zero/1.0/) applies to the data made available in this article, unless otherwise stated in a credit line to the data.
} 


\section{Background}

Aging population is posited as a social challenge at global level. It reflects in older ages at which mental functioning becomes significantly impaired [1]. Cognitive impairment, including dementia as one outcome of decline in cognitive ability increases considerably with the rapidly growing population of older adults [2]. Worldwide, almost $80 \%$ of the general public are concerned about developing dementia at some point of time and 1 in 4 people think that they can do nothing to prevent dementia [3]. Further, evidence suggests an aggregate effect of socio-economic risk factors on cognitive impairment among older adults $[4,5]$.

Persons with higher cumulative socio-economic status (SES) demonstrated an advantage in cognitive functioning [6]. Growing body of literature suggests that the older adults with higher accumulation of wealth may be able to more easily translate it into better circumstances or less stressful living conditions, further contributing to better cognitive health in later life [5, 7-9]. Studies in developing countries have also demonstrated that social networks and familial support are major factors that provide older adults mental reserves and enhance their wellbeing especially those from poor resource settings [10-12]. On the other hand, people with low income, low education, lack of support networks or lack of access to appropriate health or social services are all at a greater risk for poor health conditions that are, in turn, risk factors for declining cognitive ability [13]. However, studies reported improvements in mental well-being for older people after the introduction of an income supplemental program $[14,15]$, indicating that individual income status has a major contribution to late life wellbeing. Similarly, recent research has revealed that self-perceived income sufficiency assessment is a useful tool both theoretically and practically, in an underserved population where participants may be more reluctant to report their income levels than their perceived income status [16].

Furthermore, a major contributing factor may include poor literacy resulting in an inability to benefit from resources on strategies to early prevention of cognitive impairment [17-19]. In multiple studies that measured late-life cognitive impairment by a test of processing speed, it was found that educational attainment and current poverty index were associated with cognition $[5$, 20, 21]. Furthermore, each SES indicator shows different financial resources, social prestige and diverse skills of an individual [4]. While the spousal loss can cause emotional distress accompanied by bereavement, widowhood status accelerates cognitive impairment over time among widowed older adults $[22,23]$. Studies also found that difficulty in activities of daily living, poor self-reported health, status of being bedridden and depressive symptoms are significantly associated with cognitive impairment $[24,25]$. Further, multi-morbidity and sematic comorbidities were also associated with faster declines in geriatric cognition [26].

Greater socioeconomic and gender disparities in health among older individuals in India have been well investigated [27-29]. Much studies in other countries have established that poor financial status was associated with worse cognitive function due to limited resources and health-related deprivations $[9,30,31]$. Previous studies on cognitive functioning among older adults in India focussed on gender, work status and regional variations [32-34]. However, the association of several social, economic and health-related factors with cognitive impairment that may help identify the intervention strategies that are likely to result in better cognitive health and a successful ageing is poorly understood in Indian context.

Since greater cognitive performance has been shown to be associated with better mental and physical health and lower mortality $[35,36]$. The present study contributes to the existing literature on the linkages of selfperceived income sufficiency and cognitive impairment. Study also provides additional insights on socioeconomic and health status that is associated with cognitive impairment in older ages by assessing a population based survey in India. We hypothesize that:

$\mathrm{H}_{1}$ : Self-perceived income sufficiency of older adults is positively associated with cognitive functioning, independent of other socio-demographic and health-related variables.

$\mathrm{H}_{2}$ : Older adults' working status is positively associated with cognitive impairment.

$\mathrm{H}_{3}$ : Education, asset ownership and household economic status would each be associated with cognitive functioning among older adults, such that higher levels of each would predict better cognitive status.

\section{Data and methods \\ Data}

Data for this study is derived from the BKPAI (Building Knowledge Base on Population Ageing in India) which was carried out in India. A primary survey was carried out in seven states of India (Himachal Pradesh, Punjab, West Bengal, Odisha, Maharashtra, Kerala and Tamil $\mathrm{Nadu}$ ), that covered a total of 9852 elders from 8329 elderly households in rural and urban areas. As these states have a higher percentage of the $60+$ population compared to the national average and these states also represent all regions of the country. The individual's questionnaire was used which covers on the sociodemographic profile, work history, and benefit, income, and assets, living arrangement, social activities, the health status of elderly \& social security related question 
[37]. The BKPAI sample design entails a two-stage probability sampling. Where first villages were classified into different strata on the basis of population size, and the number of primary sampling units (PSUs) to be selected was determined in proportion to the population size of each stratum. Using probability proportional to population size (PPS) technique, the PSUs have been chosen, and within each selected PSU, elderly households were selected through systematic sampling. A similar procedure was applied in drawing samples from urban areas [37]. The final sample size for the analysis after removing missing cases was 9176 older adults.

\section{Variable description \\ Outcome variable}

The outcome variable was binary and was assessed though verbal recall strategy in the questionnaire [37, 38]. To measure cognitive impairment, a scale of 0 to 10 was prepared representing higher the score lower the cognitive impairment [10]. Five or more words were recoded as 0 "low" representing lower cognitive impairment and score of four or less was recoded as 1 "high" representing higher cognitive impairment [1]. Coginitve impairment represents poor coginitve ability among older adults. This survey has used immediate recall of words to assess the degree of cognitive impairment among older adults [1]. Immediate recall has worked as a reliable test to measure cognitive ability among elderly in different studies [39-41]. The words used for testing cognitive impairment were Bus, House, Chair, Banana, Sun, Bird, Cat, Saree, Rice, and Monkey which are commonly used in Indian scenario [41].

\section{Explanatory variable}

Self-perceived income sufficiency was recoded as (no income, has income and fully sufficient, has income and partially sufficient and has income and not sufficient), working status was recoded as (never worked, currently working and retired), educational status was recoded as (no education, below five years, 6-10 years and 11+ years), marital status was recoded as (not in union and currently in union), asset ownership was asked regarding home ownership, land ownership, jewellery ownership and other monetary savings and was recoded as (no and yes), age was recoded as (60-69 years, 70-79 years and $80+$ years). Co-residing with children was recoded as (no and yes).

Self-rated health (SRH) was having a scale of 1 to 5 "poor to excellent" and was categorized as 0 "good" (representing good, very good and excellent) and 1 "poor" (representing poor or fair) [42]. Ability to do activities of daily living (ADL) was having a scale of 0 to 6 where in it represents higher the score higher the independence. A score of was categorized as 0 "high" which represents full independence and 5 and less was categorized as 1 "low" which represents not fully independent to do activities of daily living (Cronbach Alpha: 0.93) [43]. Ability to do instrumental activities of daily living (IADL) was having a scale of 0 to 8 representing higher the score higher the independence. A score of $6+$ was categorized as 0 "high" representing high IADL and score of 5 and less was recoded as 1 "low" representing low IADL [40].

The 12-item version of the General Health Questionnaire (GHQ-12) was used as a measure of low psychological health. Developed by Goldberg in the 1970s, this measure has been extensively used to measure the psychological or mental health status in different settings and different cultures [44]. Psychological health was having a scale of 0 to 12 on the basis of experiencing stressful symptoms and was recoded as 0 "high" (representing $6+$ scores) and 1 "low" (representing score 5 and less) $[45,46]$. The low psychological health represents lower levels of psychological health or psychological distress among older adults (Cronbach alpha: 0.90). The 9-item subjective well-being questionnaire was used to measure low subjective well-being. Subjective wellbeing was having a scale of 0 to 9 and was categorized as 0 "high" experiencing better experience (representing 6+ scores) and 1 "low" experiencing negative experience (representing score 5 and less) [47]. Twelve questions on psychological health and nine questions on subjective wellbeing were asked to assess the outcome. All the questions were asked on Likert scales and were recoded and used accordingly as per literature $[10,40]$. The low subjective well-being represents lower levels of subjective well-being among older adults (Cronbach alpha: 0.93).

Wealth index was categorized in five quintile i.e. poorest, poorer, middle, richer and richest [48], religion was recoded as Hindu, Muslim, Sikhs and others, caste was available as Scheduled Caste, Scheduled Tribe, Other Backward Class and Other [48] and place of residence was available as rural and urban. Data was collected in seven states of India to make it representable i.e., Himachal Pradesh, Punjab, West Bengal, Odisha, Maharashtra, Kerala and Tamil Nadu.

\section{Statistical analysis}

Descriptive analysis along with bivariate analysis was used to find the plausible association between cognitive impairment with exposure and potential risk factors using the chi-square test [49]. Apart from binary logistic regression analysis [50] was used to provide the relationship between cognitive impairment and other risk factors. The software used was STATA 14. The significance level was set to be $5 \%(p<0.05$. R-Squared is the proportion of variance in the dependent variable (cognitive impairment) which can be predicted from the independent 
variables. When analysing data with a logistic regression, an equivalent statistic to R-squared does not exist. The model estimates from a logistic regression are maximum likelihood estimates arrived at through an iterative process. They are not calculated to minimize variance, so the OLS approach to goodness-of-fit does not apply. However, to evaluate the goodness-of-fit of logistic models, several pseudo R-squared have been developed. A pseudo R-squared only has meaning when compared to another pseudo R-squared of the same type, on the same data, predicting the same outcome. In this situation, the higher pseudo R-squared indicates which model better predicts the outcome [51, 52]. Additionally, variance inflation factor was computed to check the multicollinearity among the variables used [53, 54]. It was found that there was no evidence of multicollinearity among the variables used in this study. Moreover, svyset command [55] in STATA 14 [56] was used to control for complex survey design. Individual level weights which were available in the dataset were used during the analyses.

\section{Results}

Table 1 represents the socio-economic and demographic profile of older adults in India. Responding to the question on self-perceived income sufficiency, about $43 \%$ of older adults reported that they had no source of income. Nearly $67 \%$ of older adults did not work in the last one year period. Almost half of the older adults had no education at the time of survey. Nearly $40 \%$ of older adults were not in a marital union. About $18 \%$ of older adults had no asset ownership. One in tenth of the older adults were from the age group 80 years and above. More than $50 \%$ of older adults were women and slightly less than $50 \%$ were men. About $29 \%$ of older adults were not co-residing with their children. More than half of the older adults in India reported that they had poor SRH; about $57 \%$ reported that they had low IADL and about $7 \%$ had low ADL. Nearly $27 \%$ and $24 \%$ had low subjective well-being and low psychological health. About $24 \%$ of older adults belong to poorest wealth status and 15\% belong to richest wealth status. Nearly, $80 \%$ of the population belong to Hindu religion and $21 \%$ of the study population belong to Scheduled Caste category. About $26 \%$ of the study population belong to urban areas.

Table 2 presents percentage of older adults with cognitive impairment by background characteristics among older adults in India. Older adults who had income but not sufficient to fulfil their basic needs had highest percentage of cognitive impairment (71.1\%). Older adults who never worked had highest percentage of cognitive impairment (66.0\%). Older adults with no education
(70.6\%) had highest percentage of cognitive impairment. Being not in a marital union (68.9\%) was a significant risk factor for cognitive impairment. About $71.6 \%$ of older adults with no asset ownership had cognitive impairment in comparison to 57.5 with asset ownership. Oldest old (78.5\%), older women (66.3\%) and older adults co-residing with children (60.9\%) had higher percentage of cognitive impairment. Older adults with poor SRH (69\%), low IADL (68.0\%), low ADL (87.7\%), low subjective well-being (74.6\%) and low psychological health $(76.5 \%)$ had higher percentage of cognitive impairment. Being from a poorest wealth status (71.2\%) possesses the extreme risk of high percentage of cognitive impairment among older adults. Older adults from rural background (63.0\%) had higher percentage of cognitive impairment.

Figure 1 represents percentage of cognitive impairment among older adults by their working status as by choice or compulsion. Older adults who work by other compulsions $(73.3 \%)$ had highest percentage of cognitive impairment.

Figure 2 reveals percentage of cognitive impairment among older adults by their mental or physical stress due to work. Older adults who felt mental or physical stress (57.6\%) had highest percentage of cognitive impairment.

Table 3 represents logistic regression estimates for cognitive impairment by background characteristics among older adults in India. The table consists of four models. Model-1 holds individual level factors including demographic factors. Model-2 holds health factors which are at individual level but focus on health issues. Model3 holds household level factors and model-4 is the full effect model. The model fit is explained using pseudo $R$ square and Negelkerke R-square which explain the variance in the model. R-squared measures the strength of the relationship between the model and the dependent variable on a convenient $0-100 \%$ scale. Model-1 followed by model- 3 and model- 2 explains the variation for cognitive impairment. However, model-4 had the highest $\mathrm{R}$ square values as it is the full effect model. This signifies that individual level factors followed by household and health factors explain the variation in cognitive impairment among older adults in India.

Older adults with income but partially sufficient to fulfil their basic needs had 39\% significantly higher likelihood to suffer from cognitive impairment than older adults who had income that was fully sufficient [OR: 1.39; OR: 1.21-1.59]. Older adults who were retired had $23 \%$ significantly lower likelihood to suffer from cognitive impairment than older adults who did not work in the last one year period [OR: 0.77; CI: 0.63-0.94]. Older adults with 11 and more years of education had $72 \%$ significantly lower likelihood to suffer from 
Table 1 Socio-economic and demographic profile of older adults in India

Variables

Self-perceived income sufficiency

Has income and fully sufficient

Has income and partially sufficient

Has income and not sufficient

No income

Working status (last one year)

Never worked

Currently working

Retired

\section{Educational status}

No education

Below 5 years

6 to 10 years

$11+$ years

\section{Marital status}

Not in union

Currently in union

\section{Asset ownership}

No

Yes

Age group (in years)

60-69

70-79

$80+$

Sex

Men

Women

Co-residing with children

No

Yes

Self-rated health

Good

Poor

IADL

High

Low

ADL

High

Low

Subjective well-being

High

Low

Psychological health
Sample

Percentage

2156

2410

26.3

661

7.2

3949

43.0

6174

67.3

2208

24.1

794

8.7

4654

50.7

1890

20.6

2072

22.6

559

3632

39.6

5544 
Table 1 Socio-economic and demographic profile of older adults in India (Continued)

\begin{tabular}{|c|c|c|}
\hline Variables & Sample & Percentage \\
\hline Low & 2152 & 23.5 \\
\hline \multicolumn{3}{|l|}{ Wealth status } \\
\hline Poorest & 2170 & 23.7 \\
\hline Poorer & 2024 & 22.1 \\
\hline Middle & 1903 & 20.7 \\
\hline Richer & 1708 & 18.6 \\
\hline Richest & 1370 & 14.9 \\
\hline \multicolumn{3}{|l|}{ Religion } \\
\hline Hindu & 7299 & 79.6 \\
\hline Muslims & 644 & 7.0 \\
\hline Sikh & 847 & 9.2 \\
\hline Others & 386 & 4.2 \\
\hline \multicolumn{3}{|l|}{ Caste } \\
\hline Scheduled Caste & 1897 & 20.7 \\
\hline Scheduled Tribe & 515 & 5.6 \\
\hline Other Backward Class & 3353 & 36.5 \\
\hline Others & 3411 & 37.2 \\
\hline \multicolumn{3}{|l|}{ Place of residence } \\
\hline Rural & 6783 & 73.9 \\
\hline Urban & 2393 & 26.1 \\
\hline \multicolumn{3}{|l|}{ State } \\
\hline Himachal Pradesh & 1456 & 15.9 \\
\hline Punjab & 1240 & 13.5 \\
\hline West Bengal & 1127 & 12.3 \\
\hline Orissa & 1453 & 15.8 \\
\hline Maharashtra & 1230 & 13.4 \\
\hline Kerala & 1340 & 14.6 \\
\hline Tamil Nadu & 1330 & 14.5 \\
\hline Total & 9176 & 100.0 \\
\hline
\end{tabular}

IADL Instrumental activities of daily living, $A D L$ Activities of daily living

cognitive impairment than older adults who were uneducated [OR: 0.28; CI: 0.22-0.35]. Older adults who were currently in a marital union had $16 \%$ significantly lower likelihood to suffer from cognitive impairment than older adults not in a union.

Likelihood of cognitive impairment was low among older adults with asset ownership than older adults with no asset ownership [OR: 0.83; CI: 0.72-0.95]. Being in oldest old age group, the odds of cognitive impairment was high among such population [OR: 1.92; CI: 1.592.32]. Older adults with poor SRH [OR: 1.28; CI: $1.15-$ 1.42], low IADL [OR: 1.26; CI: 1.13-1.40], low ADL [OR: 1.91; CI: 1.51-2.42], low subjective well-being [OR: 1.13; CI: 1.04-1.29] and low psychological health [OR: 1.58; CI: 1.37-1.82] had higher likelihood to suffer from cognitive impairment than their counterparts. Older adults from richest wealth status had significantly lower likelihood to suffer from cognitive impairment than older adults from poorest wealth status [OR: 0.69; CI: 0.56-0.85]. Older adults from West Bengal [OR: 4.40; CI: 3.55-5.45], Kerala [OR: 2.35; CI:1.93-2.87] and Orissa [OR: 1.65 ; CI: $1.37-1.99$ ] had significantly higher odds to suffer from cognitive impairment than older adults from Himachal Pradesh.

\section{Discussion}

The study used a large cross-sectional data to investigate the association of major socio-economic and healthrelated variables with cognitive impairment among older adults. Our study made a few important findings, which provide a comprehensive understanding of the impact of socio-economic deprivations and worse health status on 
Table 2 Percentage of older adults with cognitive impairment by background characteristics among older adults in India

Self-perceived income sufficiency

Has income and fully sufficient

Has income and partially sufficient

Has income and not sufficient

No income

Working status (last one year)

Never worked

Currently working

Retired

Educational status

No education

Below 5 years

63.6

6 to 10 years

40.8

$11+$ years

\section{Marital status}

Not in union

Currently in union

\section{Asset ownership}

No

Yes

Age group (in years)

60-69

70-79

$80+$

Sex

Men

Women

\section{Co-residing with children}

No

Yes

Self-rated health

$$
\text { Good }
$$

Poor

IADL

High

Low

ADL

High

Low

Subjective well-being

High

Low

Psychological health

High
71.6

57.5

53.1

68.2

78.5

53.0

66.3

57.8

60.9

48.9

69.0

49.6

68.0 
Table 2 Percentage of older adults with cognitive impairment by background characteristics among older adults in India (Continued)

\begin{tabular}{|c|c|c|}
\hline Variables & Percentage & $p<0.05$ \\
\hline Low & 76.5 & \\
\hline Wealth status & & * \\
\hline Poorest & 71.2 & \\
\hline Poorer & 65.1 & \\
\hline Middle & 60.1 & \\
\hline Richer & 48.7 & \\
\hline Richest & 48.7 & \\
\hline Religion & & * \\
\hline Hindu & 59.6 & \\
\hline Muslims & 67.1 & \\
\hline Sikh & 56.1 & \\
\hline Others & 64.0 & \\
\hline Caste & & * \\
\hline Scheduled Caste & 66.2 & \\
\hline Scheduled Tribe & 71.4 & \\
\hline Other Backward Class & 56.5 & \\
\hline Others & 58.3 & \\
\hline Place of residence & & * \\
\hline Rural & 63.0 & \\
\hline Urban & 51.6 & \\
\hline State & & * \\
\hline Himachal Pradesh & 54.2 & \\
\hline Punjab & 54.9 & \\
\hline West Bengal & 81.9 & \\
\hline Orissa & 69.3 & \\
\hline Maharashtra & 55.0 & \\
\hline Kerala & 66.3 & \\
\hline Tamil Nadu & 40.7 & \\
\hline Total & 60.0 & \\
\hline
\end{tabular}

*if $p<0.05$; IADL: Instrumental activities of daily living; ADL: Activities of daily living

cognitive impairment among older people. Results of the study revealed that older individual's perceived income status that is sufficient and meets their basic needs was associated with better cognitive functioning. Our finding is supported by a recent study that found that selfperceived income status is positively associated with life satisfaction, happiness, and overall mental wellbeing [57]. Many previous studies have found that poor financial status was associated with worse cognitive functioning $[2,9,31,58]$. A longitudinal study on health benefits associated with the additional income shows that relative to the control site, there was a statistically significant improvement in memory and overall health of older adults who are provided with an additional income [59]. Participants in the same study used their extra income to go to the doctor, buy their medications, and alleviate their hunger and with basic health improvements, their cognitive abilities started to improve.

Another key SES indicator that is analysed in this population-based study is working status of older adults. Results show that older adults who had never worked for last one year had the highest odds for impaired cognition compared to those who are retired or currently working after adjusting for socio-economic and health factors. Moreover, another interesting picture appears with the higher chances of cognitive impairment among currently working older adults than those who are retired. Since a large proportion of older adults in present study continue to engage in work by compulsion or to overcome financial distress and were associated with 


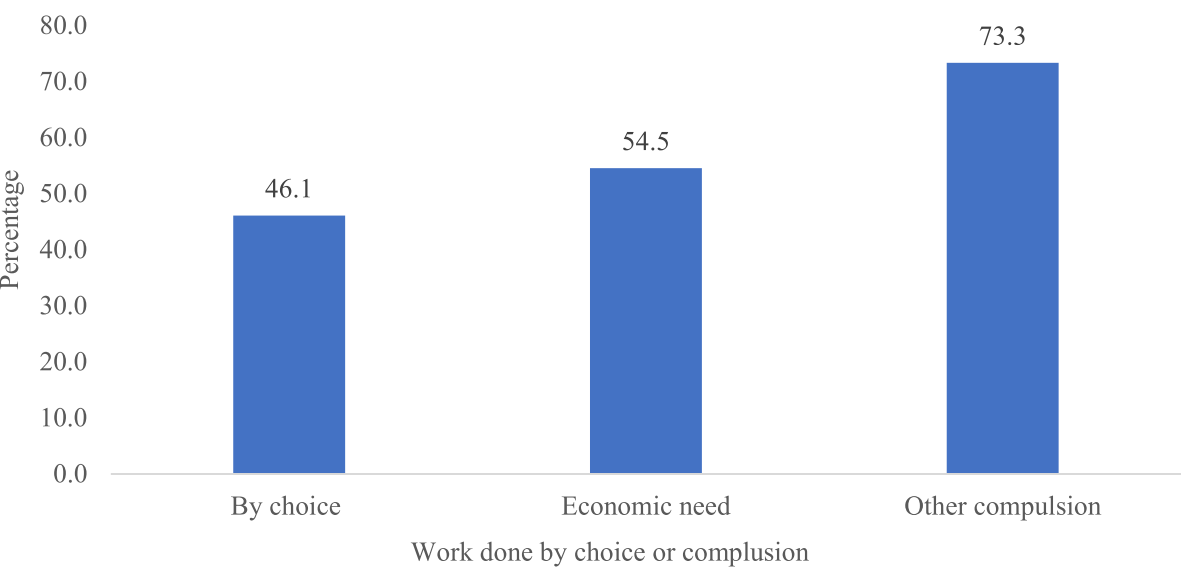

Fig. 1 Percentage of cognitive impairment among older adults by their working status as by choice, economic need or compulsion

mental or physical stress, the results do not support the notion that current working status is associated with better cognitive outcome [60]. The finding is also contrary to studies in developed countries that demonstrated that working in an occupation characterized by higher levels of mental demands was associated with better cognitive functioning before retirement, and a slower rate of cognitive impairment after retirement [61, 62]. However, in consistence with our finding, recent studies in developing countries suggest that retirement also provides a fair opportunity to engage in longpending social activities, also known as the 'honeymoon effect' and reduce negative feelings so as to optimize cognitive functioning [63-65]. Other research suggests that retirement and involvement in voluntary activities, meeting with relatives, and participation in other social activities results in cognitive preservation [66]. Although many studies including ours establish an association of working status with cognitive functioning, inconsistencies remain in most studies on the causality. Thus, longitudinal studies are further warranted in different cultural settings.

Further, current income status may be a poor indicator of financial resources because income may drop with retirement even if wealth is at its life-time peak [67]. Particularly for older adults, income is a less complete assessment of economic status than wealth is, because it does not reflect the value of accumulated assets such as home and other property [68]. after controlling the socio-demographic and health factors, it was found that having no asset ownership had a statistically significant association with cognitive impairment. The finding is supported by a study that showed better cognitive performance of older adults who had accumulated substantial wealth as asset just as they approached the point in their life cycle when they rely on their wealth to protect them against the increasing risk of health events [7]. However, a voluminous literature suggests that education has the strongest association with cognitive functioning, followed by current material circumstances $[1$,

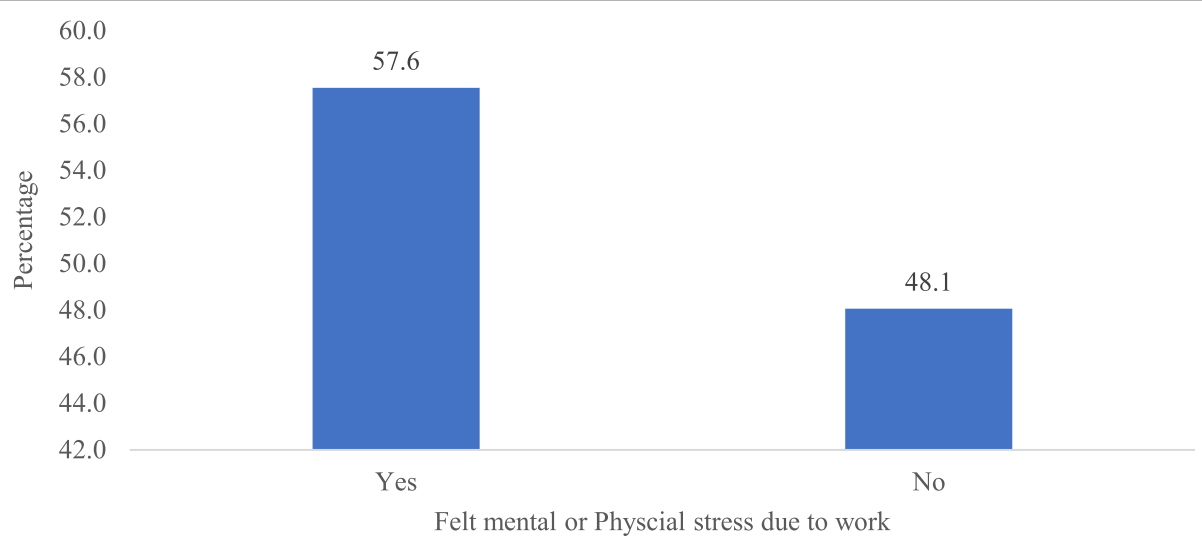

Fig. 2 Percentage of cognitive impairment among older adults by their mental or physical stress due to work 
Table 3 Logistic regression estimates for cognitive impairment by background characteristics among older adults in India

\begin{tabular}{|c|c|c|c|c|}
\hline \multirow[t]{2}{*}{ Variables } & Model-1 & Model-2 & Model-3 & Model-4 \\
\hline & OR $(95 \% \mathrm{Cl})$ & OR $(95 \% \mathrm{Cl})$ & OR $(95 \% \mathrm{Cl})$ & OR $(95 \% \mathrm{Cl})$ \\
\hline \multicolumn{5}{|l|}{ Self-perceived income sufficiency } \\
\hline Has income and fully sufficient & Ref. & & & Ref. \\
\hline Has income and partially sufficient & $1.92 *(1.69,2.19)$ & & & $1.39 *(1.21,1.59)$ \\
\hline Has income and not sufficient & $2.37^{*}(1.92,2.92)$ & & & $1.34^{*}(1.07,1.68)$ \\
\hline No income & $1.50^{*}(1.30,1.72)$ & & & $1.25 *(1.07,1.45)$ \\
\hline \multicolumn{5}{|l|}{ Working status (last one year) } \\
\hline Never worked & Ref. & & & Ref. \\
\hline Currently working & $0.84^{*}(0.74,0.97)$ & & & $0.88(0.76,1.02)$ \\
\hline Retired & $0.64^{*}(0.53,0.77)$ & & & $0.77^{*}(0.63,0.94)$ \\
\hline \multicolumn{5}{|l|}{ Educational status } \\
\hline No education & Ref. & & & Ref. \\
\hline Below 5 years & $0.74^{*}(0.65,0.83)$ & & & $0.69 *(0.6,0.79)$ \\
\hline 6 to 10 years & $0.40^{*}(0.36,0.45)$ & & & $0.45^{*}(0.39,0.52)$ \\
\hline $11+$ years & $0.27^{*}(0.22,0.32)$ & & & $0.28 *(0.22,0.35)$ \\
\hline \multicolumn{5}{|l|}{ Marital status } \\
\hline Not in union & Ref. & & & Ref. \\
\hline Currently in union & $0.80^{*}(0.72,0.89)$ & & & $0.84^{*}(0.75,0.95)$ \\
\hline \multicolumn{5}{|l|}{ Asset ownership } \\
\hline No & Ref. & & & Ref. \\
\hline Yes & $0.71 *(0.63,0.81)$ & & & $0.83^{*}(0.72,0.95)$ \\
\hline \multicolumn{5}{|l|}{ Age group (in years) } \\
\hline $60-69$ & Ref. & & & Ref. \\
\hline $70-79$ & $1.65^{*}(1.48,1.84)$ & & & $1.48 *(1.32,1.66)$ \\
\hline $80+$ & $2.38^{*}(2,20.83)$ & & & $1.92 *(1.59,2.32)$ \\
\hline \multicolumn{5}{|l|}{ Sex } \\
\hline Men & Ref. & & & Ref. \\
\hline Women & $0.91(0.81,1.03)$ & & & $1.04(0.92,1.18)$ \\
\hline \multicolumn{5}{|l|}{ Co-residing with children } \\
\hline No & Ref. & & & Ref. \\
\hline Yes & $0.96(0.87,1.07)$ & & & $0.95(0.85,1.07)$ \\
\hline \multicolumn{5}{|l|}{ Self-rated health } \\
\hline Good & & Ref. & & Ref. \\
\hline Poor & & $1.75^{*}(1.60,1.92)$ & & $1.28 *(1.15,1.42)$ \\
\hline \multicolumn{5}{|l|}{ IADL } \\
\hline High & & Ref. & & Ref. \\
\hline Low & & $1.72 *(1.58,1.88)$ & & $1.26 *(1.13,1.40)$ \\
\hline \multicolumn{5}{|l|}{$A D L$} \\
\hline High & & Ref. & & Ref. \\
\hline Low & & $2.19 *(1.76,2.72)$ & & $1.91 *(1.51,2.42)$ \\
\hline \multicolumn{5}{|l|}{ Subjective well-being } \\
\hline High & & Ref. & & Ref. \\
\hline Low & & $1.57^{*}(1.40,1.77)$ & & $1.13 *(1.04,1.29)$ \\
\hline
\end{tabular}

Psychological health 
Table 3 Logistic regression estimates for cognitive impairment by background characteristics among older adults in India (Continued)

\begin{tabular}{|c|c|c|c|c|}
\hline \multirow[t]{2}{*}{ Variables } & Model-1 & Model-2 & Model-3 & Model-4 \\
\hline & OR $(95 \% \mathrm{Cl})$ & OR (95\% Cl) & OR $(95 \% \mathrm{Cl})$ & OR $(95 \% \mathrm{Cl})$ \\
\hline High & & Ref. & & Ref. \\
\hline Low & & $1.56^{*}(1.37,1.77)$ & & $1.58^{*}(1.37,1.82)$ \\
\hline \multicolumn{5}{|l|}{ Wealth status } \\
\hline Poorest & & & Ref. & Ref. \\
\hline Poorer & & & $0.88(0.76,1.02)$ & $1.08(0.92,1.27)$ \\
\hline Middle & & & $0.64^{*}(0.55,0.75)$ & $0.93(0.78,1.11)$ \\
\hline Richer & & & $0.43^{*}(0.37,0.51)$ & $0.71^{*}(0.59,0.86)$ \\
\hline Richest & & & $0.32^{*}(0.27,0.38)$ & $0.69 *(0.56,0.85)$ \\
\hline \multicolumn{5}{|l|}{ Religion } \\
\hline Hindu & & & Ref. & Ref. \\
\hline Muslims & & & $1.21(0.99,1.47)$ & $0.90(0.73,1.11)$ \\
\hline Sikh & & & $1.04(0.84,1.30)$ & $0.93(0.73,1.17)$ \\
\hline Others & & & $1.27^{*}(1.01,1.59)$ & $1.30 *(1.02,1.65)$ \\
\hline \multicolumn{5}{|l|}{ Caste } \\
\hline Scheduled Caste & & & Ref. & Ref. \\
\hline Scheduled Tribe & & & $0.85(0.68,1.08)$ & $1.01(0.79,1.29)$ \\
\hline Other Backward Class & & & $0.89(0.77,1.02)$ & $0.98(0.84,1.14)$ \\
\hline Others & & & $0.82^{*}(0.72,0.93)$ & $0.96(0.84,1.11)$ \\
\hline \multicolumn{5}{|l|}{ Place of residence } \\
\hline Rural & & & Ref. & Ref. \\
\hline Urban & & & $0.80^{*}(0.72,0.88)$ & $0.90(0.81,1.01)$ \\
\hline \multicolumn{5}{|l|}{ State } \\
\hline Himachal Pradesh & & & Ref. & Ref. \\
\hline Punjab & & & $1.33^{*}(1.09,1.63)$ & $1.16(0.93,1.44)$ \\
\hline West Bengal & & & $4.14^{*}(3.42,5.02)$ & $4.40 *(3.55,5.45)$ \\
\hline Orissa & & & $1.64^{*}(1.39,1.95)$ & $1.65^{*}(1.37,1.99)$ \\
\hline Maharashtra & & & $1.04(0.88,1.23)$ & $1.15(0.96,1.38)$ \\
\hline Kerala & & & $2.09^{*}(1.75,2.5)$ & $2.35^{*}(1.93,2.87)$ \\
\hline Tamil Nadu & & & $0.57^{*}(0.48,0.69)$ & $0.59 *(0.48,0.72)$ \\
\hline Pseudo R-Square & 0.11 & 0.07 & 0.08 & 0.17 \\
\hline Negelkerke R-Square & 0.18 & 0.13 & 0.15 & 0.28 \\
\hline
\end{tabular}

OR Odds Ratio, Cl Confidence Interval; ${ }^{*}$ if $p<0.05$; IADL Instrumental activities of daily living, ADL Activities of daily living; Ref: Reference

4, 69]. Concordantly, our study also found a statistically significant positive association between higher-educated older adults and better cognitive functioning compared to those without formal education. Although the education-cognition relationship may in part reflect an SES gradient, the association is more likely due to the process and consequences of education itself [70]. education benefits cognitive health in later life primarily by providing cognitive reserve, which in turn provides resilience to age-related neuropathology [69]. A recent study found that individuals having low levels of education and those belonging to poorer wealth quintiles experience a stressful impact on cognition in old age [65].

Marital status in the present study was significantly associated with cognitive impairment. It is possible that sharing one's life with a partner results in stimulating brain activities and as a result, married persons could have lower speed of cognitive decline [71]. Further, because of the stigma of dependency and care burden, many older parents are reluctant to ask for financial assistance or care from their adult children [39, 72] 
indicating that co-residence with children may not be a protective factor of cognitive impairment in old age. Consistently, we observed no statistically significant association of co-residence with cognitive impairment in present study. In agreement with earlier studies, higher cognitive impairment in present study was observed in older adults with low subjective health, low psychological health, poor SRH and deterioration in ADL and IADL. Further, subjective losses of daily functioning have been described as features of mild cognitive impairment and the significant association is well documented in many previous studies [73-76]. Our findings consistent with previous studies, suggest that in a low socioeconomic setting with no awareness or preparedness for mental health problems, Western models of care arrangements would be inappropriate, therefore, familybased care settings could be a way forward [77, 78].

The present study however had certain limitations. Since the results of this study are based on crosssectional data, study limits our ability to establish causality. Further, the data was collected from seven states of India which represents six regions of India. Therefore, even being a nationally representative study, one has to be cautious while generalizing the results. However, study has its own strengths too. The study includes large sample size with a national representation and the data is rich with information on older adults' self-perceived income status and ageing-related issues in Indian scenario.

\section{Conclusion}

Our findings suggest that poor economic status is independently associated with cognitive impairment in Indian adults over age 60 years. Older adults with lower levels of any of the health indicators were at increased risk for cognitive impairment whereas, higher levels of education and household wealth status were major protective factors of cognitive impairment in old age. Thus, the study highlights the pressing need for care and support and especially financial incentives in the old age to preserve cognitive health. While planning geriatric health care for older adults, priority must be given to financially backward, with no asset ownership, with poor health status, older-older, widowed, and illiterate older individuals, as they are more vulnerable to cognitive impairment.

To reduce cognitive impairment in later life, policy makers should pay more attention to reducing socioeconomic deprivation by implementing programs and policies based on each component of SES separately. Policies increasing social capital by educating, increasing access to health care, reducing economic inequality, and promoting positive health- related behaviours may enhance the cognitive health of low-SES individuals.
Moreover, establishing an early diagnosis may enable older adults and their family members prepare for the future in an appropriate way. Also, further investigation is required to examine the sociocultural and regional differences in the association of SES and cognitive ageing that can help discern factors and inform the development of preventive strategies.

\section{Abbreviations}

SRH: Self-rated health; ADL: Activities of daily living; IADL: Instrumental activities of daily living; OR: Odds ratio; Cl: Confidence Interval; BKPAl: Building a Knowledge Base on Population Aging in India

\section{Acknowledgements}

Not applicable.

\section{Authors' contributions}

(i) MT, SS and TVS made a substantial contribution to the concept or design of the work; or acquisition, analysis or interpretation of data. (ii) MT and SS drafted the article or revised it critically for important intellectual content, (iii) MT, SS and TVS approved the version to be published, (iv) MT, SS and TVS each author have participated sufficiently in the work to take public responsibility for appropriate portions of the content. The authors read and approved the final manuscript.

\section{Authors' information}

Muhammad T completed his M.Phil. in Population studies and is currently pursuing his Ph.D. in Population studies from International Institute for Population Sciences, Mumbai, India. His areas of interest include dimentions of socioeconomic status and mental health status among older adults. Shobhit Srivastava completed his M.Phil. in Population studies and is currently pursuing his Ph.D. in Population studies from International Institute for Population. His area of interest is ageing and Mental Health issues among older adults.

T.V Sekher is Professor and Head at Department of Population Policies and Programmes at International Institute for Population Sciences, Mumbai, India. His areas of interest are Social Demography, Gender Issues, Population Ageing, Health Services and Management, Reproductive and Child Health, History of Population and Health, Family Studies, Social Welfare Programs.

Funding

Authors did not receive any funding to carry out this research.

Availability of data and materials

The study utilises secondary source of data which is freely available in public domain through http://www.isec.ac.in/

\section{Declarations}

\section{Ethics approval and consent to participate}

The data is freely available in public domain and survey agencies that conducted the field survey for the data collection have collected a prior consent from the respondent. Local ethics committee of Institute for Social and Economic Change, Bangalore, ruled that no formal ethics approval was required to carry out research from this data source.

\section{Consent for publication}

Not applicable.

\section{Competing interests}

The authors declare that they have no competing interests.

Received: 27 December 2020 Accepted: 3 May 2021

Published online: 17 May 2021

\section{References}

1. Skirbekk V, Loichinger $E$, Weber D. Variation in cognitive functioning as a refined approach to comparing aging across countries. Proc Natl Acad Sci U S A. 2012;109(3):770-4. https://doi.org/10.1073/pnas.1112173109. 
2. Wu F, Guo Y, Zheng Y, et al. Social-economic status and cognitive performance among Chinese aged 50 years and older. PLoS One. 2016;11: $1-9$.

3. Alzheimer's Disease International. World Alzheimer Report 2019 Attitudes to dementia 2019.

4. Lee $\mathrm{Y}$, Back JH, Kim J, Byeon H. Multiple socioeconomic risks and cognitive impairment in older adults. Dement Geriatr Cogn Disord. 2010;29(6):523-9. https://doi.org/10.1159/000315507.

5. Zhang Z, Gu D, Hayward MD. Early life influences on cognitive impairment among oldest old Chinese. J Gerontol Ser B Psychol Sci Soc Sci. 2008;63:25-33.

6. Lyu J, Burr JA. Socioeconomic status across the life course and cognitive function among older adults: an examination of the latency, pathways, and accumulation hypotheses. J Aging Health. 2016;28(1):40-67. https://doi. org/10.1177/0898264315585504.

7. Hamoudi A, Dowd JB. Housing wealth, psychological well-being, and cognitive functioning of older Americans. J Gerontol Ser B Psychol Sci Soc Sci. 2014;69:253-62.

8. Sha T, Yan Y, Cheng W. Associations of childhood socioeconomic status with mid-life and late-life cognition in Chinese middle-aged and older population based on a 5-year period cohort study. Int J Geriatr Psychiatry. 2018;33(10):1335-45. https://doi.org/10.1002/gps.4930.

9. Bajaj JS, Riggio O, Allampati S, Prakash R, Gioia S, Onori E, et al. Cognitive dysfunction is associated with poor socioeconomic status in patients with cirrhosis: an international multicenter study. Clin Gastroenterol Hepatol. 2013;11(11):1511-6. https://doi.org/10.1016/j.cgh.2 013.05.010.

10. Joe W, Perkins JM, Subramanian SV. Community involvement, trust, and health-related outcomes among older adults in India: a population-based, multilevel, cross-sectional study. Age Ageing. 2019;48(1):87-93. https://doi. org/10.1093/ageing/afy154.

11. Tripathi RK, Tiwari SC. Cognitive dysfunction in normally aging urban older adults: A community-based study. Indian J Psychol Med Epub ahead of print. 2011;33(2):177-81. https:/doi.org/10.4103/0253-7176.92059.

12. Srivastava $\mathrm{S}$, Purkayastha $\mathrm{N}$, Chaurasia $\mathrm{H}$, et al. Socioeconomic inequality in psychological distress among older adults in India : a decomposition analysis. BMC Psychiatry. 2021;21:1-15.

13. Yeh SJ, Liu Y. Influence of social support on cognitive function in the elderly. BMC Health Serv Res. 2003:9:1-9.

14. Galiani S, Gertler P, Bando R. Non-contributory pensions. Labour Econ. 2016; 38:47-58. https://doi.org/10.1016/j.labeco.2015.11.003.

15. Salinas-Rodríguez A, Torres-Pereda MDP, Manrique-Espinoza B, et al. Impact of the non-contributory social pension program 70 y más on older adults' mental well-being. PLoS One. 2014;9:1-10.

16. Tarasenko YN, Schoenberg NE, Schoenberg NE. Self-perceived Income sufficiency and self-reported Income level among a health inequity population. J Health Care Poor Underserved. 2017;28(2):812-28. https://doi. org/10.1353/hpu.2017.0076

17. Manly JJ, Min T, Yaakov S. Literacy and memory decline among ethnically diverse elders. J Clin Exp Ncuropsychol. 2003;25(5):680-90. https://doi.org/1 0.1076/jcen.25.5.680.14579

18. Hanson KL, Connor LM. Food insecurity and dietary quality in US adults and children: a systematic review. Am J Clin Nutr. 2014;100(2):684-92. https:// doi.org/10.3945/ajcn.114.084525.

19. Portela-Parra ET, Leung CW. Food insecurity is associated with lower cognitive functioning in a National Sample of older adults. J Nutr. 2019; 149(10):1812-7. https://doi.org/10.1093/jn/nxz120.

20. Al Hazzouri AZ, Haan MN, Kalbfleisch JD, et al. Life-course socioeconomic position and incidence of dementia and cognitive impairment without dementia in older Mexican Americans: results from the Sacramento area Latino study on aging. Am J Epidemiol. 2011;173(10):1148-58. https://doi. org/10.1093/aje/kwq483.

21. Zhang M, Gale SD, Erickson LD, Brown BL, Woody P, Hedges DW. Cognitive function in older adults according to current socioeconomic status. Aging Neuropsychol Cogn. 2015;22(5):534-43. https://doi.org/10.1080/13825585.2 014.997663

22. Perrig-Chiello P, Spahni S, Höpflinger F, et al. Cohort and gender differences in psychosocial adjustment to later-life widowhood. J Gerontol Ser B Psychol Sci Soc Sci. 2016;71:765-74.

23. Shin SH, Kim G, Park S. Widowhood status as a risk factor for cognitive decline among older adults. Am J Geriatr Psychiatry. 2018;26(7):778-87. https://doi.org/10.1016/j.jagp.2018.03.013.
24. Konda PR, Sharma PK, Gandhi AR, et al. Correlates of Cognitive Impairment among Indian Urban Elders. J Gerontol Geriatr Res. 7. https://doi.org/10.41 72/2167-7182.1000489 Epub ahead of print 2018.

25. Sharma D, Mazta S, Parashar A. Prevalence of cognitive impairment and related factors among elderly: a population-based study. J Dr NTR Univ Heal Sci. 2013;2(3):171. https://doi.org/10.4103/2277-8632.117182

26. Wei MY, Levine DA, Zahodne LB, Kabeto MU, Langa KM. Multimorbidity and cognitive decline over 14 years in older Americans. J Gerontol A Biol Sci Med Sci. 2020;75(6):1206-13. https://doi.org/10.1093/gerona/glz147.

27. Arokiasamy P, Kowal P, Capistrant BD, et al. Chronic noncommunicable diseases in 6 low-and middle-income countries: findings from wave 1 of the World Health Organization's study on global ageing and adult health (SAGE). Am J Epidemiol. 2017;185(6):414-28. https://doi.org/10.1093/aje/ kww125.

28. Vellakkal S, Subramanian SV, Millett C, Basu S, Stuckler D, Ebrahim S. Socioeconomic inequalities in non-communicable diseases prevalence in India: disparities between self-reported diagnoses and standardized measures. PLoS One. 2013;8(7):e68219. https://doi.org/10.1371/journal.pone. 0068219.

29. Biritwum RB, Minicuci N, Yawson AE, Theou O, Mensah GP, Naidoo N, et al. Prevalence of and factors associated with frailty and disability in older adults from China, Ghana, India, Mexico, Russia and South Africa. Maturitas. 2016;91:8-18. https://doi.org/10.1016/j.maturitas.2016.05.012.

30. Chen X, Huang Y, Cheng HG. Lower intake of vegetables and legumes associated with cognitive decline among illiterate elderly Chinese: a 3-year cohort study. J Nutr Heal Aging. 2012;16(6):549-52. https://doi.org/10.1007/ s12603-012-0023-2.

31. Xu X, Liang J, Bennett JM, et al. Socioeconomic stratification and multidimensional health trajectories: evidence of convergence in later old age. J Gerontol Ser B Psychol Sci Soc Sci. 2015;70:661-71.

32. Chanda S, Mishra R. Impact of transition in work status and social participation on cognitive performance among elderly in India. BMC Geriatr. 19. Epub ahead of print 2019. https://doi.org/10.1186/s12877-019-1261-5.

33. Kumar H, Arokiasamy $P$, Selvamani Y. Socioeconomic disadvantage, chronic diseases and their association with cognitive functioning of adults in India: a multilevel analysis. J Popul Ageing. 2020;13(3):285-303. https://doi.org/10.1 007/s12062-019-09243-9.

34. Singh PK, Jasilionis D, Oksuzyan A. Gender difference in cognitive health among older Indian adults: a cross-sectional multilevel analysis. SSM Popul Heal. 2018;5:180-7. https://doi.org/10.1016/j.ssmph.2018.06.008.

35. Batty GD, Deary IJ, Gottfredson LS. Premorbid (early life) IQ and later mortality risk: systematic review. Ann Epidemiol. 2007;17(4):278-88. https:// doi.org/10.1016/j.annepidem.2006.07.010.

36. Jokela $M$, Singh-manoux A, Ferrie JE, et al. The association of cognitive performance with mental health and physical functioning strengthens with age: the Whitehall II cohort cohort study. Psychol Med. 2011;40:837-45.

37. UNFPA. Report on the status of elderly in selected states of India: building a knowledge base on ageing in India. New Delhi: United Nations Population Fund; 2012.

38. Krueger LE, Salthouse TA. Influence of cognitive abilities and age on word recall performance across trials and list segments. Am J Psychol. 2011;124(3): 291-300. https://doi.org/10.5406/amerjpsyc.124.3.0291.

39. Muhammad T, Srivastava S. Why Rotational Living Is Bad for Older Adults ? Evidence from a Cross- Sectional Study in India. J Popul Ageing. 1. Epub ahead of print 2020. https://doi.org/10.1007/s12062-020-09312-4.

40. Srivastava S, Muhammad T. Violence and associated health outcomes among older adults in India : a gendered perspective. SSM Popul Heal. 2020;12:100702. https://doi.org/10.1016/j.ssmph.2020.100702.

41. Muhammad T, Govindu M, Srivastava S. Relationship between chewing tobacco, smoking, consuming alcohol and cognitive impairment among older adults in India: a cross-sectional study. BMC Geriatr. 2021;21(1):85. https://doi.org/10.1186/s12877-021-02027-x.

42. Srivastava S, Chauhan S, Patel R. Socio-Economic Inequalities in the Prevalence of Poor Self-Rated Health among Older Adults in India from 2004 to 2014: A Decomposition Analysis. Ageing Int. 2021;46:182-99. https://doi.org/10.1007/s12126-020-09385-8.

43. Muhammad T, Srivastava S. Why rotational living is bad for older adults ? Evidence from a cross- sectional study in India why rotational living is bad for older adults ? Evidence from a cross-sectional study in India. Epub ahead of print 2020. DOl: https://doi.org/10.1007/s12062-02009312-4. 
44. Goldberg DP, Blackwell B. Psychiatric Illness in General Practice: A Detailed Study Using a New Method of Case Identification. Br Med J Epub ahead of print 1970. 2(5707):439-43. https://doi.org/10.1136/bmj.2.5707.439.

45. Jacob KS, Bhugra D, Mann AH. General health questionnaire - 12: psychometric properties and factor structure among INDIAN women living in the United Kingdom. Indian J Psychiatry. 1997;39(3):196-9.

46. Shidhaye R, Patel V. Association of socio-economic, gender and health factors with common mental disorders in women: a population-based study of 5703 married rural women in India. Int J Epidemiol. 2010;39(6): 1510-21. https://doi.org/10.1093/ije/dyq179.

47. Sell H. The subjective well-being inventory (SUBI). Int J Ment Health. 1994; 23(3):89-102. https://doi.org/10.1080/00207411.1994.11449289.

48. Srivastava S, Kumar S. Does socio-economic inequality exist in micronutrients supplementation among children aged 6-59 months in India? Evidence from National Family Health Survey 2005-06 and 2015-16. BMC Public Health. 2021;21:545. https://doi.org/10.1186/s12889-021-10601-6.

49. Mchugh ML. The chi-square test of independence lessons in biostatistics. Biochem Medica.

50. Osborne J, King JE. Binary logistic regression. In: Best Practices in Quantitative Methods: SAGE Publications, Inc.; 2011. p. 358-84.

51. Long JS, Freese J. Models for binary outcomes in regression models for categorical dependent variables, using Stata. 2006;2(1). https://doi.org/10.11 86/2051-3933-2-4 Epub ahead of print 2006.

52. Long JS. Regression Models for Categorical and Limited Dependent Variables. J Am Stat Assoc. 1997;7: p 92

53. Lewis-Beck M, Bryman A, Futing Liao T. Variance Inflation Factors. In: The SAGE Encyclopedia of Social Science Research Methods; 2012. Epub ahead of print 2012. https://doi.org/10.4135/9781412950589.n1067.

54. Vogt W. Variance Inflation Factor (VIF). In: Dictionary of Statistics \& Methodology; 2015. Epub ahead of print 2015. https://doi.org/10.4135/ 9781412983907.n2059.

55. Rafferty A. Introduction to Complex Sample Design: Workbook

56. StataCorp. Stata: Release 14. Statistical Software. 2015

57. Yu H. Income Comparison and Subjective Well-Being: Evidence from SelfPerceived Relative Income Data from China: Palgrave Macmillan UK; 2020. https://doi.org/10.1057/s41302-020-00168-2. Epub ahead of print 2020

58. Wee LE, Yeo WX, Yang GR, Hannan N, Lim K, Chua C, et al. Individual and area level socioeconomic status and its association with cognitive function and cognitive impairment (low MMSE) among community-dwelling elderly in Singapore. Dement Geriatr Cogn Dis Extra. 2012;2(1):529-42. https://doi. org/10.1159/000345036.

59. Aguila E, Kapteyn A, Smith JP. Effects of income supplementation on health of the poor elderly: the case of Mexico. Proc Natl Acad Sci U S A. 2015; 112(1):70-5. https://doi.org/10.1073/pnas.1414453112.

60. Bonsang $E$, Adam S, Perelman S. Does retirement affect cognitive functioning? J Health Econ. 2012;31(3):490-501. https://doi.org/10.1016/j. jhealeco.2012.03.005.

61. Fisher GG, Infurna FJ, Grosch J, et al. Mental work demands, retirement, and longitudinal trajectories of cognitive functioning. J Occup Health Psychol. 2014;19(2):231-42. https://doi.org/10.1037/a0035724.

62. Clouston SAP, Denier N. Mental retirement and health selection: analyses from the U.S. health and retirement study. Soc Sci Med. 2017;178:78-86. https://doi.org/10.1016/j.socscimed.2017.01.019.

63. Shanker S, Mukku R, Harbishettar V, et al. Psychological Morbidity after Job Retirement : A Review. Asian J Psychiatr Epub ahead of print. 2018;37:58-63. https://doi.org/10.1016/j.ajp.2018.08.003.

64. Pinto JM, Neri AL. Factors related to low social participation in older adults: findings from the Fibra study, Brazil. Cadernos Saúde Coletiva. 2017;25:286-93.

65. Fernández-Niño JA, Bonilla-Tinoco LJ, Manrique-Espinoza BS, RomeroMartínez M, Sosa-Ortiz AL. Work status, retirement, and depression in older adults: an analysis of six countries based on the study on global ageing and adult health (SAGE). SSM Popul Heal. 2018;6:1-8. https://doi.org/10.1016/j. ssmph.2018.07.008.

66. de Grip A, Dupuy A, Jolles J, van Boxtel M, et al. SSRN Electron J. Epub ahead of print. 2012. https://doi.org/10.2139/ssrn.2149479.

67. Smith JP, Kington R. Demographic and economic correlates of health in old age. Demography. 1997;34(1):159-70. https://doi.org/10.2307/2061665.

68. Kogevinas M, Pearce $N$, Susser $M$, et al. The measurement of social class in health studies : old measures and new formulations. IARC Sci Publ. 1997; 138: p 51
69. Brayne C, Ince PG, Keage HAD, McKeith IG, Matthews FE, Polvikoski T, et al. Education, the brain and dementia: Neuroprotection or compensation? Brain. 2010;133(8):2210-6. https://doi.org/10.1093/brain/awq185.

70. Cagney KA, Lauderdale DS. Education, wealth, and cognitive function in later life. J Gerontol Ser B Psychol Sci Soc Sci. 2002;57:163-72.

71. Wu MS, Lan TH, Chen CM, et al. Socio-demographic and health-related factors associated with cognitive impairment in the elderly in Taiwan. BMC Public Health. 11. Epub ahead of print 2011. https://doi.org/10.1186/1471-24 58-11-22.

72. Walsh F. Families in later life: challenges, opportunities, and resilience. Expand Fam life cycle. 2010:261-77.

73. Reppermund S, Brodaty H, Crawford JD, Kochan NA, Draper B, Slavin MJ, et al. Impairment in instrumental activities of daily living with high cognitive demand is an early marker of mild cognitive impairment: the Sydney memory and ageing study. Psychol Med. 2013:43(11):2437-45. https://doi. org/10.1017/S003329171200308X.

74. Patel BB, Holland WN. Mild cognitive impairment: Hope for stability, plan for progression. Cleve Clin J Med. 2012;79(12):857-64. https://doi.org/10.3949/ ccjm.79a.11126

75. Okonkwo OC, Griffith HR, Vance DE, Marson DC, Ball KK, Wadley VG. Awareness of functional difficulties in mild cognitive impairment: a multidomain assessment approach. J Am Geriatr Soc. 2009:57(6):978-84. https:// doi.org/10.1111/j.1532-5415.2009.02261.x.

76. Miu J, Negin J, Salinas-Rodriguez A, et al. Factors associated with cognitive function in older adults in Mexico. Glob Health Action. 9. Epub ahead of print 2016. https://doi.org/10.3402/gha.v9.30747.

77. Patel V, Prince M. Ageing and mental health in a developing country: who cares? Qualitative studies from Goa, India. Psychol Med. 2001;31(1):29-38. https://doi.org/10.1017/S0033291799003098.

78. Seby K, Chaudhury S, Chakraborty R. Prevalence of psychiatric and physical morbidity in an urban geriatric population. Indian J Psychiatry. 2011;53(2): 121-7. https://doi.org/10.4103/0019-5545.82535.

\section{Publisher's Note}

Springer Nature remains neutral with regard to jurisdictional claims in published maps and institutional affiliations.

Ready to submit your research? Choose BMC and benefit from:

- fast, convenient online submission

- thorough peer review by experienced researchers in your field

- rapid publication on acceptance

- support for research data, including large and complex data types

- gold Open Access which fosters wider collaboration and increased citations

- maximum visibility for your research: over $100 \mathrm{M}$ website views per year

At $\mathrm{BMC}$, research is always in progress.

Learn more biomedcentral.com/submission 